\title{
RESPONDING TO ECONOMIC CRISES: POLICY ALTERNATIVES FOR EQUITABLE RECOVERY AND DEVELOPMENT
}

\author{
by \\ JOSEPH STIGLITZ \\ The World Bank
}

\begin{abstract}
While economic crises are becoming more frequent and severe, our experience in East Asia has demonstrated how the international response to these crises remains inadequate. Appropriate policy responses to economic crises entail three essential dimensions: first, the maintenance of full employment and economic stability through macroeconomic policy; second, complementary structural policy aimed at restoring confidence; and finally, a robust social safety net to mitigate the adverse and potentially long-term effects of economic downturns. A suitable crisis response requires that policy-makers recognize the critical role of financial markets and the existence of time lags. Suitable policy responses should consider not only an individual economy's ability to absorb shocks, but also the asymmetries and nonlinearities of alternative policies. As we thus seek to improve our macroeconomic and structural policies for the future prevention and mitigation of crises, it is critical that we bear in mind the protection of the most vulnerable segments of society from the crises that will inevitably occur.
\end{abstract}

Economic crises can produce large and rapid increases in inequity. Indonesia's poverty rate had drifted down from over 60 per cent in 1975 to 7 per cent just prior to the crisis. It is now expected to rise to around 20 per cent by the year 2000. In Korea more than 1 million people have lost their jobs, and many others face lower real wages and less job security. Thailand has also seen increasing poverty, unemployment, and falling real wages. Altogether, prior to the crisis there were 30 million people living on less than $\$ 1$ a day in Indonesia, Malaysia, the Philippines and Thailand. By 2000 that number could easily double to 60 million.

The most important policy for socially equitable development is full employment. The unemployed are not just a statistic or an under-utilized resource that could have increased GDP. They are people, and no numbers can convey the degree of disruption that unemployment brings to their lives, their livelihoods, and the well-being of their families. Although safety nets and targeted assistance may mitigate some of the consequences of unemployment, from an economic, political or psychological perspective, nothing is better than a job. Jobs are the means by which people participate in the productive economy and feel productive themselves. It is one of the most important sources of inclusion in the national economy.

(c) Blackwell Publishers Ltd and The Victoria University of Manchester, 1999.

Published by Blackwell Publishers Ltd, 108 Cowley Road, Oxford OX4 1JF, UK, and 350 Main Street, Malden, MA 02148, USA 
In the context of developing countries, minimizing underemployment is just as important as minimizing unemployment. If an Indonesian loses his or her well-paying factory job, they can always return to their village and help out on the family farm. The extra output from their effort, however, may be minimal, making their 'job' virtually equivalent to unemployment.

In the short run, and crisis situations are first and foremost about the short run, macroeconomic policy is the most important determinant of the level of economic activity and thus the level of employment. This will be the first subject of my remarks. Second, I will discuss structural policies which also can be of great importance for social well-being, especially in the way that they interact with macroeconomic policies. Finally, I will argue that full employment is only the first defense; it is often necessary to employ unemployment insurance, targeted social assistance, and other social safety net programs that maintain people's incomes and ease their transition into future jobs.

\section{Macroeconomic Policy and Maintaining Full Employment}

\subsection{Macroeconomic Policy Can Do More Harm Than Good}

In designing macroeconomic policies, policy-makers face a peculiar constraint: although the wrong policies can result in virtually unbounded harm, the right policies can only keep the economy operating normally. It is relatively easy to use monetary and fiscal policy to engineer a 25 per cent contraction-some argue that this is what the USA did, albeit inadvertently, in the Great Depression. It is virtually impossible, however, to use monetary and fiscal policy to expand the economy by 25 per cent. This idea is often expressed, particularly in the context of monetary policy, by analogy to a balloon on a string: Tightening the string can pull the economy down, but pushing on the string cannot push the economy back up.

The consequences of policy are asymmetric for several other reasons as well. First, a relatively small shock to the economy may be selfcorrecting, but a larger shock may plunge the economy into a recession. In economists' technical jargon, we say that nonlinearities are very important.

Bankruptcy provides an illustration of both the push-pull and nonlinear phenomena. With a big enough push, you can bring many of the economy's firms into bankruptcy, but reversing that process is far more difficult. As the economy deteriorates, a large number of firms go bankrupt, and their mutual obligations raise uncertainty and increase bankruptcy even more. The result is a large decrease in production, investment and credit flows, with the attendant consequences for output 
and unemployment. The huge costs associated with resolving bankruptcies make it very difficult to repair the damage. Also, the organizational capital that is the firm's core asset dissipates quickly after it is shut down and rebuilding that organizational capital is a lengthy process. This is reflected in the well-known observation that the value of a firm as an ongoing enterprise is far greater than the value of the assets which constitute it.

A second, and related, reason for lopsided policy results is the abundant evidence that a period of bad economic performance can be translated into a prolonged period of higher unemployment and slower growth. In addition to the reasons just discussed, this can occur because firms respond to bad times by reducing their investment in research and development. Furthermore, long-term unemployed workers lose their jobsearching skills and become stigmatized by employers - an effect economists have called hysteresis. Many economists place at least a share of the blame for high European unemployment in the last 15 years on hysteresis.

Finally, the social consequences of economic performance are highly uneven. Even if everyone shares the losses, the effects on the poor, who have just enough to survive, are enormous compared with the effects on those who are better off. But typically the burden of adjustment is not shared equally. A disproportionate share of the increase in unemployment or underemployment is concentrated among the least well off. As a result, these 'innocent bystanders', who played no part in the causes leading up to the crisis, are the ones who bear the greatest burden.

The asymmetries in burden sharing are not only inequitable, they also may attenuate the incentives to avoid future crises. Although I am discussing the response to crises, we must be mindful that the way in which we respond to crises, or are expected to respond to crises, helps shape the incentives that make crises more or less likely. If, for instance, crises are typically precipitated by a build-up of short-term debt, and if short-term debtors do not share in the losses, or even if they do not bear the full costs of their actions, then they will be encouraged to continue making risky loans. Improving the burden sharing is not solely a matter of social justice.

\subsection{Policy Decisions Must Recognize Uncertainty}

The asymmetry between the potentially devastating consequences of bad macroeconomic policy and the simply 'normal' consequences of good macroeconomic policy would not matter if policy-makers could choose the outcome they most wanted. But they cannot. Macroeconomic policy is conducted under conditions of great uncertainty. There are, for instance, 
what my Stanford colleague Milton Friedman described as 'long and variable lags' between changes in monetary policy and their effect on the economy. Fiscal policy is more direct. But because policy affects expectations in difficult-to-predict ways, and expectations in turn impact interest rates and exchange rates, the final effects of policy remain uncertain. This is especially true in crisis situations.

As a result, policy-makers must make important decisions in less than ideal circumstances. If they make the wrong decision, the country can collapse. If they make the right decision, hardly anyone notices. These decisions are made in a highly uncertain environment. They must recognize this uncertainty, recognize the asymmetries, and recognize the longlasting effects of possible mistakes.

How they should respond to uncertainties depends on the situation of the economy-including its history. One example that illustrates some of the considerations in decision making under uncertainty comes from monetary policy decisions in the USA in the mid-1990s. Although the stakes - relatively small changes in the unemployment rate or inflationand the complexity of the decisions were much smaller than entailed by macroeconomic decisions in crisis situations, the logic of the argument may be easier to follow in this context.

In conducting monetary policy, the principal uncertainty the USA faced concerned the lack of knowledge about the precise level of the NAIRU, the unemployment rate below which inflation starts to rise. The conventional wisdom had been that the NAIRU was 6.0 or 6.2 per cent, but this rate was inconsistent both with the behavior of inflation and several well-documented structural changes in the economy. More important than the precise level of the NAIRU, however, was the assessment of the risks entailed by making a mistake on either side, and the costs of reversing such a mistake. Partly these depended on the initial conditions: inflation was already low, while unemployment rates, especially for marginalized groups, were intolerably high. Risks also depended on the precise slope and shape of the Phillips curve relating unemployment to changes in inflation. Analysis by the Council of Economic Advisers concluded that the additional inflation from 'too low' an unemployment rate was relatively small, and that it could be reversed by a period of even lower unemployment.

The result of our analysis was the assessment that the risk and consequences of igniting an inflationary episode were negligible: the views of the inflation hawks were simply not justified by the data. On the other side, we estimated that the potential benefits to the economy could be quite large. Beside contributing to faster growth, reductions in unemployment could help address social problems, including the 20 -year-long trend of increasing exclusion for poor and minority workers, the rising welfare case load, and the soaring crime rate. The USA did take the risk and allowed (c) Blackwell Publishers Ltd and The Victoria University of Manchester, 1999. 
the unemployment rate to fall, and the benefits have been even better than we predicted, especially in their contribution to the plunging welfare case loads and the dramatically falling crime rate. I strongly believe that these decisions were the right decisions, not just because ex post the outcome has been consistent with our predictions, but also because they were based on a good ex ante analysis of the risks.

\subsection{Macroeconomic Policy and the Onset of the East Asian Crisis}

In an economy facing a crisis, the balance of risks should be a central focus of discussion. Again, the situation of the economy, including its historical context, is central. Consider the East Asian countries, with a long history of stable macroeconomic policies, fiscal surpluses and low inflation. For instance, in the year before the crisis, Korea had brought its inflation rate down from $5 \frac{1}{2}$ per cent to 4 per cent. The entire region was roughly in macroeconomic balance at the time the crises struck. As consumption and investment were likely to plummet, standard macroeconomic models suggested the likelihood of a serious drop in GDP. Given that the countries were starting from rough macroeconomic balance, this contraction in the key components of demand would lead to a large increase in unemployment or underemployment. Given the asymmetries and nonlinearities I discussed earlier, this situation strongly implied that it would be better to err on the side of countercyclical policy to offset these declines at least partially.

Three other considerations should have played a key role in the study of the problems facing East Asia and the policy response to them. Many of these issues were a part of our investigation from the beginning, and I do not want to engage in after-the-fact analysis; but if we do not fully understand the response to this crisis, we risk repeating the same mistakes in responding to future crises.

First let us consider the importance and uncertainty of lags, a point which I referred to earlier in the context of monetary policy. Lags are especially large and unpredictable in the domain of exports, say in responses to changes in exchange rates. These lags featured greatly in our thinking about macroeconomic policy in the USA, and should have played an even more important role given the magnitude of the risks, the nonlinearities and irreversibilities. If one believes that these nonlinearities, irreversibilities and lags are important, one cannot say that if the economy goes into a downturn we will reverse course. By then, the damage will be done. One must balance the risks and recognize the asymmetries. In macroeconomic policy making, one must keep ahead of the game, not running behind. This requires, among other measures, careful monitoring of data, a process which is difficult in many developing economies where timely data on the current state of the economy are often relatively scarce. Still, in 
Southeast Asia, for instance, early data on sales of cars and other consumer durables clearly indicated, almost in real time, the magnitude of the real economic contraction and raised questions about the wisdom of the region's macroeconomic stance. And to the degree that data are highly incomplete, this additional uncertainty needs to be incorporated explicitly into policy decisions.

Second, theory and empirical evidence over the past two decades have established the importance of financial markets, their links with the macroeconomy, the role that financial crises play in economic downturns, and the fact that economic downturns that are precipitated or accompanied by banking and currency crises are deeper and longer than, say, downturns associated with inventory cycles. It was clear that the crises in East Asia were financial crises, and this raised a warning flag about the risks being faced, and therefore should have affected the policy stance. A familiarity with the financial structure in East Asia suggested that the risks they would face, in this regard, were far more severe than those that had been encountered in earlier crises.

Third, and most importantly, a risk analysis must take into account the ability of the economy - its workers and others within society-to absorb various shocks, including unemployment and underemployment. The East Asian countries lacked social safety nets, suggesting that they faced grave risks: the social costs of an economic downturn might be an order of magnitude greater than in Finland, where the country experienced a huge increase in unemployment as a result of its financial crises but had in place a strong social welfare system. In countries with social and political fragilities, risks to the people in the economy can have strong consequences. Severe economic downturns systematically stir social and political unrest that in turn worsen the economic downturn, according to extensive economic and political research, to say nothing of common sense.

\subsection{Political Economy}

Given these risks, it is clear how most politicians would behave: they would push for a policy that minimizes the risk of exacerbating the crisis. Indeed, given that political risks are also asymmetric, there is even a concern that they might push too hard.

In many parts of the world, the recognition of this asymmetry of political response has led to measures that take key parts of macroeconomic policy out of the hands of politicians and put them in the jurisdiction of an independent central bank. At the international level, too, those responding to crises are not directly accountable to those affected by the crises.

Now, people are increasingly concerned that responses are designed

(C) Blackwell Publishers Ltd and The Victoria University of Manchester, 1999. 
to reflect the interests of those who have voices in these independent institutions, and that those voices are not representative of the groups affected by the decisions. Of course, independence does not necessarily entail unrepresentativeness, but empirical studies find a marked correlation.

We need to recognize that different policies impose different risks on different groups within the population. Attitudes toward those risks, and balancing those differential effects, are not just technical matters, but reflect value judgments and trade-offs which should be an essential part of the political process. These cannot simply be left to technical experts, at least not in democratic societies. When technical experts are closely aligned with the interests of one group, and are disproportionately drawn from that group, it is not surprising that the policies may exhibit some disregard toward other groups.

We may talk about the pain of adjustment, we may talk about how everyone shares the pain, but the record suggests that neither the pain of adjustment nor the gain associated with the factors precipitating the crisis were equitably shared. I shall return to this theme later on.

\subsection{Economic Strength versus Investor Confidence: Is there a Trade-off?}

It has become an article of faith that countries in crisis must have done something wrong, and that they can only recover if they punish themselves with austerity measures. The more severe the crisis, according to this view, the greater the sins and thus the greater the required penance. This runs completely contrary to the logic I just outlined that implied that macroeconomic policy should attempt to pre-empt severe economic contractions. Advocates of painful reforms often justify them by noting that they are 'necessary to restore confidence' and that, at least in the short run, confidence is more important than maintaining aggregate output and employment.

One year ago I questioned this dichotomy in a New York Times oped. I argued that 'maintaining a strong economy . . . is essential to restoring confidence'. The unfortunate experience of the year that has elapsed since I wrote that sentence has strongly confirmed this perspective. High interest rates were supposed to restore confidence in East Asia. Instead they weakened the economies, causing even more depreciated exchange rates and thus undermining confidence still further. Elsewhere in a Brookings paper, I have analyzed the economics of the relationship between interest rates and exchange rates in crisis situations. Briefly, the logic is that the interest rate is only the promised rate of return on domestic assets. If a higher interest rate leads to a greater probability of bankruptcy, then the expected rate of return on domestic assets may go down, leading to a weaker exchange rate. 


\subsection{Designing Macroeconomic Policies for Equitable Recovery}

Macroeconomic policy-makers typically focus on questions like the strength of multiplication effects that increase the impact of policies and on time lags in policy effectiveness. These are clearly very important issues. However, little if any consideration is given to equity, or the distributional impact of the economic policies. I have already argued that changes in aggregate output tend to be distributed unevenly, and thus inherently have consequences on the distribution of well-being. But now I want to go further and draw attention to the different distributional consequences of various policies.

The relative effects of monetary policy on different groups varies from country to country depending on institutional practices both in the private sector and in the public sector. In most economies, high interest rates tend to restrict borrowing and investment by small and medium-sized enterprises much more than by large firms. Also, substantial evidence from several countries has documented that higher interest rates can have a large adverse effect on farmers' access to credit. This is well documented, and my other theoretical research over the past decades has helped provide the explanation for this phenomenon. The distributional effects of changes in interest rates, however, depend on the degree to which different credit markets are segmented and the existence of government programs to help different groups gain access to credit. In Brazil, for instance, government programs and financial market practices have, to a large degree, delinked the interest rate faced by many farmers from the key monetary policy interest rates. In contrast, Indonesia's credit markets are tightly linked, and an increase in policy interest rates rapidly translates into higher interest rates across the board.

One implication of this observation is that, from the perspective of equity, monetary policy-makers need to take into account the existing institutional arrangements. This is especially true in the short run, while over the longer run these considerations present a compelling argument for developing institutional mechanisms to shield vulnerable groups from the most contractionary aspects of monetary policy.

Fiscal policy affects equity even more directly. A well-designed fiscal framework has automatic stabilizers that, at least on the expenditure side, tend to mitigate some of the inequitable consequences of economic downturns. The degree to which the poor and vulnerable are protected, both by automatic and discretionary policies, varies greatly from country to country. Some argue that many countries need to increase protections for the disadvantaged by creating more automatic stabilizers, especially ones that are triggered by severe recessions. I will return to some of the specific issues in the design of unemployment insurance policies when I discuss building better safety nets. 
In medicine, we have come a long way from medieval blood lettings and blaming the victims for their condition. Economic knowledge has made similar progress. It is essential that we make greater use of these insights, especially in crisis situations where the consequences of mistakes can be dramatic and long lived. Let me be clear: I am not against economic policies that entail painful adjustments. I do not, however, view pain as a virtue in itself, but as a sometimes necessary accompaniment of the appropriate policies. And that is exactly the point: if there is to be pain, it should contribute to strengthening the economy, not exacerbating economic downturns. And if there is to be pain, the pain must be shared equitably.

\section{Short-run Structural Solutions and Long-run Structural REFORMS}

Many of the same considerations that apply to the macroeconomic policy responses to crisis situations also apply to the structural policy responses. Indeed, we are increasingly recognizing that there is no clear separation between macroeconomic and structural issues. Structural weaknessessuch as weaknesses in financial systems or widespread corporate bankruptcies - have macroeconomic consequences, and mistakes have profound effects on economic structure that will take years to undo.

\subsection{Balancing the Goals of Structural Policies}

Unlike macroeconomic policies, structural policies entail a more complex balancing of different objectives. Policies need to be designed with four interrelated considerations in mind: (i) ex ante incentives, (ii) ex post incentives, (iii) distributional equity and fairness, and (iv) macroeconomic consequences. To give one illustration, financial regulation needs to ensure that borrowers and lenders have the ex ante incentive to behave prudently. After a crisis, however, the financial structure of banks and corporations changes, and policies will imply a different set of ex post incentives. Furthermore, financial regulation can have a large impact on credit flows, and thus on the macroeconomy. Finally, the considerations of equityincluding who continues to have access to credit as well as whose money bails out whom-should also be important.

Deposit insurance, for instance, was designed explicitly to reduce the likelihood of runs on banks. The macroeconomic costs of such runs, and the failure of financial institutions more broadly, can be enormous. On the other side, there are risks associated with moral hazard and regulatory forbearance. Again, policy-makers based their decision on a balancing of risks: their judgment calls reflected the interests they served, how they balanced those risks, and how they took into account those affected in alternative scenarios. 
The same issues also apply in the design of bankruptcy policies and corporate restructuring. Policies need to ensure that ex ante incentives encourage productive innovation but discourage excessive risk taking. Fairness requires that the rules not be changed midstream. But after a crisis, the huge debt overhang provides a new set of incentives that changes firms' responses to policies. And, as with the financial sector, bankruptcies have a major impact on the macroeconomy.

The balance of these considerations depends on the circumstances. In good times, the macroeconomic implications of structural policies may be less important since any contractionary consequences may be easy to offset with more expansionary macroeconomic policies. As the economy shifts from downturn to recession to depression, the balance of these objectives shifts. The ex post incentives and the macroeconomic consequences become the overriding objectives.

\subsection{Financial Responses to Crises: Preserving the Flow of Credit}

The financial system is like the brain of the economy. In a crisis it can virtually cease to function. The priority of financial policies is to keep credit flowing and to avoid the wholesale destruction of informational capital that occurs when financial institutions close down. This crisis-time shift in objective has important implications for many policies. In normal times we view high capital adequacy standards as a way to ensure prudent banking. The point of the additional capital, however, is to provide a cushion against bad times. If, in the midst of a downturn, we push banks too quickly toward 'prudent' capital adequacy ratios, we risk shutting down the flow of credit entirely. The same applies to regulatory forbearance more broadly in that we have to be more hesitant than we might normally like about shutting down problematic financial institutions.

The direct concern for equity in responding to a financial crisis may also be outweighed by the desire to avoid a large downturn, which itself would have huge adverse consequences on the well-being of the most vulnerable. Bailing out some of the better off at the expense of the taxpayers as a whole may be distasteful but unavoidable. In the USA, many of us who were concerned about equity more broadly still supported the government bailout of the Savings and Loans. However, the overall equity consequences can be influenced by other policies, especially if they diminish the perception that policy-makers are cutting out benefits for the poor in order to mitigate the financial problems of the rich, a theme I return to below.

\subsection{Maintaining Production Amidst Systemic Bankruptcies}

The procedures for handling bankruptcies in normal times and in crises should be quite different. Just as a central concern in the time of (c) Blackwell Publishers Ltd and The Victoria University of Manchester, 1999. 
crisis in addressing the problems of the financial sector should be the preservation of the flow of credit, so too the central concern in corporation organization should be maintaining production. But doing so in the midst of systemic bankruptcies is no small challenge.

In normal times, bankruptcy conveys a lot of information about the quality of a firm's management. In the context of a system-wide failure, little information about either the manager or even the firm's long-run viability is conveyed. Even a well-managed firm could easily go bankrupt simply because it failed to plan for an 80 per cent devaluation and a period of interest rates in excess of 40 per cent.

Not only is it undesirable to handle bankruptcy in the midst of a crisis in the standard way, it is probably not even feasible. There simply are not the resources - human or monetary - to address each bankruptcy individually. How can an administration possibly employ standard bankruptcy procedures when two-thirds of the firm in a country are bankrupt, which, by one estimate, is the case today in Indonesia? Furthermore, the systemic nature of the bankruptcies makes sorting out the net asset positions even more difficult than normal. Because the bankrupt firms' assets consist of claims on other firms that are also bankrupt, discovering their net worth entails solving a complicated set of simultaneous equations. A further difficulty in following normal bankruptcy procedures is that it would be very difficult to find new managers or trustees to oversee all of the restructured firms; this limits the feasibility of management changes.

Under these circumstances, the priority of corporate restructuring is to ensure that production continues with as little disruption as possible. This will often entail restoring effective governance to those who know how to manage the enterprises - the current owner-managers - while at the same time reducing their cash flow burdens. Accomplishing this may require a combination of carrots and sticks to increase the speed of the workout. An example of a measure that would probably be included is granting owners a greater equity share than they might be entitled to under absolute priority.

This raises the concerns of equity, specifically the fairness of changing the rules in midstream. To some degree, these claims may be outweighed by the greater imperative of maintaining production in the crisis. But 'the rules' themselves are inherently ambiguous in the midst of a situation that neither party to the contract explicitly agreed upon or even envisioned. How the contract would change had it explicitly included the contingency of, say, an 80 per cent devaluation and 15 per cent GDP contraction is uncertain.

\subsection{The Complementarity of Macroeconomic Policy and Structural Responses}

When macroeconomic policy is conducted in a way that maintains the health of the economy, corporations will be able to continue producing 
and banks will find themselves with fewer bad loans on their books. As a result, the processes of corporate bankruptcy workouts and financial recapitalization will be that much easier. In contrast, overly contractionary macroeconomic policies make the necessary structural reforms much more difficult.

The relationship between what economists call 'macroeconomic' and 'microeconomic' policies goes the other way as well. A series of illconceived and overly hasty bank closures can undermine the soundness of the financial system, weakening the aggregate economy and possibly making it less responsive to a monetary stimulus.

\subsection{Long-run Structural Reforms in the Midst of a Crisis}

My discussion of structural reforms in the midst of a crisis has emphasized that, just as macroeconomic policies need to be sensitive to the circumstances of the country, so too do microeconomic policies. In policy design, the balance of concerns changes dramatically as one enters a recession, and even more so as a recession turns into a depression. Just as it is wrong to design an economic policy for East Asia that fitted the circumstances of Latin America in the 1980s, it is also inappropriate to design a policy for a depression that does not fully reflect the unique characteristics of an economy in the midst of an economic collapse.

Structural policy has an important long-run dimension, one that is perhaps more central to the thinking of policy-makers than the long-run consequences of macroeconomic policy. Many reforms, like improving auditing and accounting standards, increasing capital adequacy requirements or freeing international trade, are aimed at increasing long-run efficiency and stability. They are not necessarily related to responding to the immediate problem of failed banks and bankrupt corporations.

In recent years, wide-ranging, long-term structural reforms have been at the heart of many of the crisis programs. There are two possible justifications. The first is that crises may present a unique opportunity to undertake reforms whose desirability has long been recognized but for which there is little political will in non-crisis periods. The second justification is that, to the degree that there is a perception that these structural weaknesses caused the crisis, then even reforms with only longrun economic benefits might immediately improve confidence and thus help to restore economic strength.

Not all long-term structural reforms, however, make sense in the midst of a crisis. In particular, there are three reasons why we should be cautious. The first is simply that responding to a crisis is extremely difficult and often requires the full attention of the scarce personnel of both the crisis country and the international institutions working with it. 'Overloading' the reform program may distract scarce attention away (C) Blackwell Publishers Ltd and The Victoria University of Manchester, 1999. 
from the immediate problems. Second, some reforms that are beneficial in the long run may actually harm the economy in the short run. Eliminating distortions that create 'rents', i.e. returns above the normal level, although beneficial in the long run, may exacerbate the problem of bankruptcy. Similarly, improving transparency in the midst of a crisis, under some circumstances, may reveal that the problems are much worse than anyone had realized, thus exacerbating the crisis. Third and finally, to the degree that unnecessary structural reforms are pushed into the programs by outsiders, domestic political support for the entire program may be undermined, including the parts that are essential for addressing the crisis at hand. As an aside, there was an especial reluctance in the USA to move to more transparent, more efficient bank accounting standards and risk adjustments in the midst of our banking crises in the 1980s.

The arguments for and against structural reforms that go beyond those directly related to resolving the crisis help us to understand when they are and are not justified. Perhaps the most important test is that they are genuinely desired by the crisis country, and not imposed from the outside. The second requirement is that there has long been agreement on the need to make this structural improvement. The third is that it should be related, at least in terms of perception, to the actual crisis. And the fourth is that the reform will not have directly contractionary effects in the short run.

\section{Building Better Social Safety Nets}

Even with the best efforts toward sound macroeconomic and structural policies, a country is unlikely to escape a serious balance of payments or banking crisis without a period of slower growth or even economic contraction. Experience also shows that income inequality tends to rise in periods of economic crises, structural adjustment and output contractions. Both the lower overall incomes and the shift in their distribution increase the number of people living in poverty.

\subsection{Averting Persistent Social Problems}

Even transitory economic contractions can have long-lived effects on people's well-being, and thus on economic performance. Increasing malnutrition at crucial stages of childhood, a well-documented consequence of economic contractions, can have adverse effects on the physical and mental development of children. This is true even if the crisis passes and their nutritional intake improves. Reports from Indonesia and Thailand indicate that millions of children are not returning for the 1998 school year, as their parents are unable to afford the school fees, other educational costs, or even spare their children's time. If this lasts very much longer, an entire 
generation of Southeast Asians will find that its educational development was compromised by the crisis.

Just as the poor and disadvantaged bear a disproportionate burden of the adjustment, so too do girls and women suffer much more than boys and men. In East Asia, women shared in the benefits of three decades of development. But when the crisis struck, they found themselves to be the first to lose their jobs. A large fraction of the school dropouts have been girls. In addition, reports indicate that prostitution, including child prostitution, is rising throughout East Asia.

It is certainly true on average that crises lead to worsening social well-being, especially for the poor and vulnerable. In part this is due to the direct effects of the crisis, but in part it is because in the past policy-makers have focused on macroeconomic adjustment, and ignored or even actively cut spending on social programs in an effort to reduce the overall deficit. In Thailand, for instance, the fiscal year 1998 expenditure cuts have largely left the overall health budget unaffected. But health spending for the poor has been reduced greatly: the main programs for the poor and near-poor, the health card schemes, which benefit 35 million people, have been cut by more than 50 per cent in nominal terms.

Countries do not need to cut spending for the poor during crises. Chile responded to its 1982 crisis with large-scale increases in targeted social spending. As a result, despite a GDP contraction almost as large as Indonesia's 1998 contraction, Chile enjoyed a dramatic acceleration in the decline of infant mortality.

\subsection{Social Spending Can Support Macroeconomic and Structural Policies}

Spending money on social programs can also be complementary to the macroeconomic and structural policies discussed above. In the crudest terms, expanded social spending can be a very effective way to engineer a fiscal expansion. If a fiscal expansion is spent on, for instance, physical infrastructure, then much of the money will be spent buying imports of capital equipment, blunting its expansionary consequences. Spending on social programs keeps almost all of the money in the country, potentially leading to a larger output 'multiplier'. In expanding social programs, however, it is important to be mindful of the attendant administrative difficulties, and the consequent potential for wasteful expenditures or even corruption.

Perhaps more importantly, incorporating social spending as an integral part of a reform package can increase the political and social consensus for the overall reforms. History shows that the most successful stabilization programs have been ones that were grounded in a broadbased social consensus, a point that my predecessor as chief economist of the World Bank, Michael Bruno, helped to demonstrate both as a 
researcher and as a policy-maker. The perception that a reform program is not just a bailout but a strengthened safety net for the poor and the middle class is essential for building the democratic support and social stability necessary for a successful overall program.

\subsection{Social Policy Priorities for East Asia}

In the context of East Asia, building a more robust social safety net is both more challenging and potentially more important than in other countries. For the last decades, East Asia had counted on rapid growth and lifetime employment to provide social security for its citizens. At best, they have limited unemployment insurance and only very modest social safety nets. In this context the current priorities are to protect and strengthen the current institutions and develop new measures to deal with the immediate crisis. This is especially important in four areas:

(1) Ensuring food security. Food is the basic necessity of life. Without food, children will become malnourished, with permanent consequences for later life. In the midst of a crisis there are both supply and demand problems. There may be an inadequate overall supply of food, and the food distribution system may break down. Most famines, however, are not due to a lack of availability of food, but to lack of resources in poor families to acquire the food. Given limited resources, ideally one would like to target food programs to the most needy. Even at the best of times, designing targeted programs is difficult. Administrative costs can be high, and the costs of errors-not getting the benefits to those who otherwise face malnutrition-can be enormous. But developing such programs in the midst of a crisis can be especially problematic. Just as the design of macroeconomic and structural reform programs needs to be sensitive to the nature of the crisis the country is facing and the depth of the economic downturn, so too must the design of the social safety net. In a crisis, the most fruitful focus may be on maintaining low prices for essential staple foods, like rice, while ensuring that distribution networks remain effective.

(2) Maintaining the purchasing power of vulnerable households. The importance of maintaining the purchasing power of vulnerable households cannot be overemphasized. As I noted above, lack of purchasing power, not lack of supply, has been the root cause of most famines and most malnourishment. Lack of purchasing power is leading to school dropouts and the deterioration of health. One method of achieving this objective is through the promotion of public works. In this case, effort needs to be made to ensure that they are well targeted, including balancing the needs of urban and rural dwellers, and those of women and men. A second method is to 
develop or expand the unemployment insurance system. This makes the most sense in Korea: it already has an unemployment insurance system that, despite large recent expansions, continues to leave the majority of workers without coverage. It is important to recognize that the main drawback of unemployment insurance programs, their effects on the incentives to look for work and thus on efficiency, may be much smaller in severe recessions where the marginal adverse incentive effect is minimal and, if jobs are rationed, may even disappear in the overall economy.

(3) Maintaining economic and social services for the poor, including spending on education and healthcare. One example is Indonesia's 'back-to-school' campaign which involves a five-year national program to provide scholarships for poor children along with a mass media and social mobilization effort to keep them attending school.

(4) Increasing monitoring, diagnosis and public information to ensure that we design and target social programs well.

In addition to these short-run measures, the East Asian countries have begun the process of thinking about the design of social security systems for the longer run. These reforms can be done in a way that complements other structural reforms. For instance, efforts to liberalize labor markets in Korea, and diminish lifetime employment protection, will only work well if they are complemented by an extension of the unemployment insurance system.

\subsection{The World Bank's Role in Containing the Social Consequences of the Crisis}

Prior to the crisis, the World Bank was working with a number of East Asian countries to help them continue their social progress. In the last year we have stepped up our efforts, in terms of policy advice, technical assistance and funding, to contain the social consequences of the crisis. At the same time, we are continuing to provide advice and support for longer term social safety reforms.

In terms of financing, some World Bank programs in East Asia include a $\$ 300$ million loan for a social investment project in Thailand that covers a wide range of the policy priorities discussed above; a $\$ 275$ million loan for poverty reduction in rural areas of Indonesia and substantial funding for anti-poverty programs in other areas; funding for labor markets and social safety nets in Korea; loans to increase job opportunities and access to basic social services in the Philippines; and a $\$ 300$ million Economic and Social Sector Loan to provide support for Malaysia's public expenditures on the poor. 


\section{Concluding Remarks}

Although the experience of East Asia is the direct motivation for many of my remarks, the lessons are unfortunately much more general. In the last decades, crises have become too frequent and too severe. Since 1975, there have been banking and currency crises in nearly 100 countries - with the frequency of these crises increasing over time. Prior to East Asia, we had witnessed ten cases when a banking and currency crisis struck simultaneously. The result was contractions of between 5 and 12 per cent of GDP in the year of the crisis and negative or very slow growth for several years after.

In the midst of economic crises, newspaper headlines are dominated by the falls in exchange rates and stock indices. Behind the headlines, however, are large increases in unemployment, poverty, malnutrition, child labor, and prostitution. The political, economic, psychological, and even physiological effects of these problems can persist long after the stock markets and exchange rates have recovered. Indonesia is in the midst of a full-scale depression — no euphemism, such as economic downturn, or even recession, can do justice to the situation. The situation in other countries has not reached the same extreme, but it is still too soon to know for sure the depths to which these economies will plummet, and at the very least they confront a severe recession.

The situation is intolerable. We have an international economic architecture which has led to more frequent crises, and yet our means of responding have proven inadequate. While there is much talk about pain, the poor have absorbed more than their share of the pain without sharing commensurately in the promised gain.

Let us be frank with ourselves and each other: we will not be able to prevent all crises. That is why I have devoted my remarks to responding to crises, with a special emphasis on socially equitable recovery and development. Improving the burden sharing in crisis situations has the potential to create more incentives for investors to avoid crises. At the same time, it can help maintain the social stability and political consensus that are, among other things, necessary to rebuild investor confidence and restore economic health.

We do need a new economic architecture to reduce the likelihood and severity of crises, to make it less likely that even countries that have pursued good economic policies will be battered, as they have been in recent weeks, forcing them to adopt policies which will inevitably lead to increased unemployment and more human suffering. But we need even more effective and more humane ways of responding to crises, ways that at least accord more with fundamental notions of human decency and social justice.

I have emphasized that the most effective ways of responding to crises, which most protect the interests of the poor, are ways that maintain the (c) Blackwell Publishers Ltd and The Victoria University of Manchester, 1999. 
strength of the economy. There are certain elementary lessons that I have stressed: there are asymmetries - it is easier to put an economy into a deep recession than to pull it out; there are large nonlinearities-large shocks have disproportionately larger and more irreversible effects; mistakes today have persistent consequences; lags are important; and finance is central, with financial crises being deeper and longer lived than economic downturns arising from other sources. Economies differ in their institutions, in their abilities to bear shocks, and in the extent of their social safety net. Part of maintaining the economy's strength entails undertaking structural reforms that are essential to keep the economy moving, like corporate restructuring and recapitalization of the banking system that maintain production and the flow of capital. Other longer term structural reforms may be justified if they are well motivated, will result in enhanced confidence, and do not directly undermine the economy in the short run.

Three general observations underlie my analysis of the design of responses. First, and most importantly, there are great uncertainties. The response to crises must take all of the factors I described above into account; it must balance the risks.

This brings me to the second point: different responses can have markedly different effects on different groups, and confront them with different levels and kinds of risks. The analysis of these differential effects should be of first order importance in designing crisis responses that are socially just.

In short, designing responses is not just a technical matter, to be left to technical experts. The balancing of risks and trade-offs is intrinsically a political decision, and needs to be made by those who are politically accountable. Countries should not be given a single option of the 'correct' course. That approach is wrong and misguided.

Finally, we must recognize our limitations: not only will we have only limited success in preventing crises, our responses may have only limited ability to stop the crises from developing into a recession. Knowing this, we must work hard to develop better safety nets to mitigate these adverse consequences.

I do not want to enter now into the debate about whether the policies which were put into place in the aftermath of the East Asia crisis exacerbated the downturn. The counterfactuals are always difficult: what would have happened if . . . While not all the jury may have turned in their ballots, there is a growing consensus on the matter.

Today, as macroeconomic stances have eased, and the public debate has moved on to the issues of international architecture and shifted away from the design of responses, it should be clear that controversies remain, disputes in which the same sets of considerations, the same uncertainties and risks, play out. How fast should banks be made to comply with capital adequacy standards? How strong a set of carrots and sticks need to be (C) Blackwell Publishers Ltd and The Victoria University of Manchester, 1999. 
put into place to induce corporate reorganization? What role should the public sector play? What role do supply and demand factors play in addressing problems of food security?

Humans are fallible, and so why should we expect more of human institutions? The fact that mistakes have been made, or mistakes will be made, should not be our overarching concern. There are, however, two things that do disturb me. First, I do not believe that all of the knowledge at our disposal, knowledge about lags and irreversibilities, about persistence and asymmetries, about the relationships between financial markets and economic activity, nor even the specific-country knowledge-knowledge of the difference between the East Asian economies and those of Latin America-was effectively brought to bear in the design of the responses. Our knowledge will always be imperfect, but we should strive to use what limited knowledge we have available.

Second, I do not believe that the interests of the most vulnerable, the workers and small businessmen, the farmers and the day laborers, the children whose education will be interrupted and whose future will be destroyed through malnourishment - all of those whose well-being is so adversely affected, were taken into account as fully as were the perceptions of the investment community. I am not sure their voice was heard, that either they had a seat at the table or their interests were well represented. And all of this was in the name of avoiding devaluations and preventing standstills, actions which inevitably occurred.

I do believe that we can design more effective responses to crises, responses that are more socially just. But I believe that if we are to achieve this, we must have more democratic accountability, more representativeness, in the way that the response packages are designed. We must go beyond paying lip-service to these values. In American parlance, we must give voice to Main Street and to those whose toil and work provide both our necessities and our luxuries. Are we to add to the growing divide between the haves and have nots a new inequality - an inequality in burden sharing in the increasingly frequent and deep crises? Unless we construct a new democratic international architecture that ensures that these silent voices are heard, I fear that what we have seen in East Asia is the inevitable precursor of the future. 
Copyright of Manchester School (14636786) is the property of Wiley-Blackwell and its content may not be copied or emailed to multiple sites or posted to a listserv without the copyright holder's express written permission. However, users may print, download, or email articles for individual use. 